IBAD Sosyal Bilimler Dergisi

IBAD Journal of Social Sciences

dergipark.org.tr/ibad

IBAD, 2021; (11): 343-357

DOI: $10.21733 /$ ibad. 918363

Özgün Araştırma / Original Article

\title{
Kastamonu İli Tosya İlçesi Geleneksel Kadın Başlıkları
}

Traditional Women Head-dress in Tosya-Kastamonu

Mihrinaz Söyük ${ }^{1^{*}}$

H. Serpil Ortaç²

\section{* Sorumlu yazar \\ Corresponding author}

${ }^{1}$ Arş. Gör., Ankara Hacı Bayram Veli Üniversitesi, Türkiye Res. Assist., Ankara Hacı Bayram Veli University, Turkey mihrinaz.soyuk@hbv.edu.tr

ORCID ID 0000-0003-4107-683X

${ }^{2}$ Dr. Öğretim Üyesi, Ankara Hacı Bayram Veli Üniversitesi, Türkiye Assist. Prof. Dr., Ankara Hacı Bayram Veli University, Turkey, hulya.ortac@hbv.edu.tr ORCID ID 0000-0001-8816-6416

Makale geliş tarihi / First received : 16.04.2021

Makale kabul tarihi / Accepted $\quad$ : 29.06.2021

\section{Bilgilendirme / Acknowledgement:}

\section{Yazarlar așağıdaki bil gilendirmeleri yapmaktadırlar:}

1- Araştırma ikinci yazarın danışmanlığında yazılmıştır.

3- Bu çalışmada her türlü desteğini esirgemeyen Tosya Başlık Ustası Nevin Tahtacı'ya çok teşekkür ediyorum.

4- Makalenin yazarları arasında çıkar çatışması bulunmamaktadır.

5- Makalemizde etik kurulu izni ve/veya yasal/özel izin alınmasını gerektiren bir durum yoktur.

7- Bu makalede araştırma ve yayın etiğine uyulmuştur.

This article was checked by Turnitin. Similarity Index 21\%

\section{Atıf bilgisi / Citation:}

Ortaç, H.S., Söyük, M. (2021). Kastamonu ili Tosya ilçesi geleneksel kadın başlıkları. IBAD Sosyal Bilimler Dergisi, (11), 343-357. 


\section{ABSTRACT}

Geleneksel Türk kadın başlıkları, ait olduğu yörenin ve dönemin giyinme kültürü, sosyal statü ve sosyoekonomik durumuyla ilgili bilgi veren önemli kültürel miraslardır. Geleneksel Türk kadın başlıklarının çeşitliliği Anadolu kültürünün zenginliğini yansıtmaktadır. Geçmiş ve gelecek arasında kültür köprüsü oluşturan değerlerden biri olan başlıklar, Anadolu kadınının ailedeki statüsü ve toplumdaki yeri ile ilgili bilgiler vermektedir. Başlıklarda bulunan motifler ve aksesuarlar Türk kadınının, Orta Asya ve Anadolu tarihi boyunca çok çeşitli form ve ölçülerde başlıklar kullandığını göstermektedir. Kastamonu ili Tosya ilçesi geleneksel kadın başlıkları, günümüzde varlığını özüne sadık kalarak devam ettiren önemli değerlerden biridir. Yöresel giyim kuşamın tamamlayıcısı olan başlıklar Tosya' da halen az da olsa düğünlerde, kına törenlerinde gerçek altın veya imitasyon altınlar ile bezenerek gelin kızların başlarını süslemeye devam etmektedir. Geleneksel Türk kültüründe Kastamonu ili Tosya ilçesi geleneksel kadın başlıklarının önemli bir yeri olması açısından bu makalede ele alınmıştır. Bu çalışmada Kastamonu'nun Tosya ilçesinde geçmişte kullanılmış ve bugün kullanılan başlıkların, zaman içindeki değişimleri ortaya konmuştur. Araştırmanın yöntemi, literatür taraması olarak belirlenmiştir. İlçede yapılan araştırma sonucunda inceleme, gözlem ve bulguların metne aktarılması sağlanmıştır.

\section{Anahtar kelimeler}

Başlık, Geleneksel, Kastamonu, Kültür, Tosya.
Traditional Turkish Women's head dresses are important cultural heritage giving information about the local culture an era, social status and Social-economic status of the region. The diversity of traditional Turkish Women's heads reflects the richness of Anatolian culture. One of the values that constitute a cultural bridge between the past and the future, It gives information about the status of Anatolian women especially in family and place in society. The motifs and accessories of the Turkish women Throughout the history of Central Asia and Anatolia, a variety of forms and sizes show the use of heads. Traditional Women's heads in Tosya district of Kastamonu province Nowadays, these values are important values that continue to be true to its essence. Complementary to the traditional clothing, the heads are often reproduced in Tosya and are used mainly at weddings. Traditional female headlines in Kastamonu province of Tosya which has an important place in our traditional culture is considered to be an important cultural heritage. In this study in Tosya district of Kastamonu The traditional Tosya Women's heads, which are used in the past and present, have been identified and their usage areas have been examined and changes have been introduced from past to present. Method of research, analysis of written sources as a result of the research conducted in the district, the examination, observations and findings were completed as a transfer to the text.

\section{Keywords}

Başlık, Geleneksel, Kastamonu, Kültür, Tosya. 


\section{GíRiş}

Biyolojik ve coğrafi ihtiyaçlar sonucunda ortaya çıkan giyinme ihtiyacı, zaman içinde ihtiyacın dışında giyinme kültürü olarak değişim göstermiş ve zamanla moda kavramını da giyinmede önemli bir etken haline getirmiştir. İklim ve tabiat şartları karşısında kendini koruma ihtiyacı hisseden insan, bu ihtiyacını kıyafetle giderebilmiştir. Yeryüzündeki farklı iklimler, insanların değişik özellikleri olan kıyafetleri giyinmelerinin yanı sıra farklı giyim anlayışları, zengin ve geniş bir giysi kültürünün gelişmesine neden olmuştur.

Giyim; insanların yeryüzünde var olduklarından beri doğa koşullarından korunma, etik anlayış ve süslenme isteği gibi nedenlerden dolayı örtünme ihtiyacı ile ortaya çıkmıştır. Tarih boyunca giyim insanların bağlı oldukları uluslara, topluluklara, kişilerin ekonomik düzeyine, sosyal ve mesleki statüsüne, yaş ve cinsiyetine bir ölçüde de özel zevkine göre değişen koşullar ve gelişmeler doğrultusunda şekillenmiş ve farklılaşmıştır. (Erdem, 2003, s.564).

Sözlük anlamı keçe, hasır, fötr vb. maddelerden çeşitli şekillerde yapılan kadınlar ya da erkekler tarafından süs olarak ya da hava şartlarından korunmak için giyilen başlık olan şapkalarda günün modasının etkisi görülmektedir. Şapka giyilmediği zamanlarda bunun yerini saç süslemeleri, özel ve anlamlı günlerde saça takılan çiçekli kep, tül, taç gibi baş süslemeleri almaktadır (Özder, 1995, s.10).

Başlık, Anadolu kadınının gündelik yaşantısında veya özel günlerinde kullandığı, giysinin tamamlayıcısı olan bir süsleme ögesi olmuştur. Anadolu'da genç kızı, yeni gelini, mutlu veya mutsuz kadını, yaslı veya yaşlı kadını başlığından tanımak mümkün olmaktadır. Başlık, bulunduğu yöreye göre farklılık gösterebilen, çeşitli malzemelerle, farklı boyutlarda üretilen bir giyim aksesuarı olarak varlığını bugüne taşıyabilmiştir.

Türk giyim kültüründe özellikle kadın kıyafetleri çok çeşitlilik göstermektedir. Kadın giyim kuşamını belirleyen etmenler arasında inançlar, gelenek-görenekler, sosyal durum, medeni hal, toplum içindeki konum, düşünce ve davranışlar önemli bir rol oynamaktadır. (Er ve Sarıkaya, 2017, s. 125).

Giyimin Anadolu'daki tarihçesi incelendiğinde çok eski kültürlerin tarih içinde sosyal ve ekonomik durum, yaş, kişilik ve toplumdaki statüsüne göre coğrafi ve tarihi özelliklerinden zaman içinde etkilenerek günümüze kadar geldiği görülmüştür (Kancan, 1998).

Anadolu topraklarını yurt edinen Türkler, yüzyıllar boyunca dil, gelenek, görenek, giyim kuşam kültürlerini ve yaşam biçimlerini Orta Asya'dan getirdikleri biçimiyle korumaya özen göstermişlerdir. Türk kadınının baş süslemelerinin vazgeçilmez öğesi olan tepelik, alınlık, yanaklık, küpe, kolye vb. tüm takılar yüzyıllardan bugüne ulaşmıştır (Balta, 2014, s.12-22).

Zengin bir birikime sahip olan Anadolu kadın giysileri her zaman estetik görünümlü, emek, sabır ve ustalık gerektiren giysilerden olmuştur. Bölgeden bölgeye değiştiği görülen bu giysileri, Kuzeydoğu, Güneydoğu, Orta Anadolu, Batı Anadolu ve Trakya giyimleri olarak gruplandırmak mümkün olduğu gibi aynı bölgede de farklılıklar görülebilmektedir. Bununla birlikte tüm bölgelerde giyilen bazı giysi türleri ortaktır. Bu giysiler entariler, şalvarlar, başlıklar, işlikler ve kuşaklar olarak sınıflandırılabilir. Ancak bunların giyiniş biçimleri ve diğer ayrıntılarında yine de bölgesel ayrılıklar görülmektedir (Özus ve Tufan, 2014, s.652). 
El Sanatları ürünleri de Anadolu'da önemli bir iletişim aracıdır. Karşılıklı ilişkileri, anlaşmaları ve statüyü simgeler. Yapıldığı dönemlere tanıklık edebildiği gibi yaşantının yoğunluk kazanmasında, kişinin doğaya ve çevresine uymasında, farklı istek ve gereksinimlerinin doyuma kavuşmasında yardımcı olmakta farklı görevler yüklenmiş bulunmaktadır. (Kazıcıoğlu, 1994, s. 271).

Süsleme insanlık tarihiyle başlamış ve insanların en doğal tutkusu olmuştur. (Özbağı, 2007, s. 1). Bunun önemli bir göstergesi de kadın kıyafetleri ve kıyafetlerin tamamlayıcısı olan başlıklardır.

Kastamonu yöresi kültürel mirasın yaşatıldığı önemli bölgelerimizdendir. Türk kültür zenginliğinin göstergesi olan ve Anadolu kadınının geçmişte günlük giysi olarak giyindiği kıyafetler günümüzde nişan, düğün, sünnet, doğum gibi özel günlerde halen giyilmektedir. Tosya ilçesine bakıldığında geleneksel başlıkların yöre kadınları için ayrı bir yeri olduğu görülmektedir. Diğer başlıkların tersine boyut olarak daha küçük ve daha çok altın bulunan başlıklar özellikle dügün ve kına gecelerinde tercih edilmektedirler. Bu açıdan geleneksel başlıkların kullanıldığı Tosya ilçesi kültürel açıdan zengin çeşitliliğe sahiptir.

Yörede kullanılan kadın kıyafetleri; üç etek sevai, çuha, canfes, bağdat, çarşafi, bindallı, meydani, kadife elbise gibi çeşitlilik gösterir. Kıyafetlerin yakaları, omuzları, göğüsleri ve etekleri gümüş veya altın simle süslenmiştir. Kıyafeti tamamlayan fes; beyaz boncuklar, inciler, pullar veya gümüş ile altın dizilip süslenerek kullanılmıştır. Fesin arkasından da yapma saç örgüleri sarkıtılmıştır. Kıyafetlerde takı olarak kullanılan “kıstı”lar özel günler dışında da kullanılmaktadır. Kıyafeti tamamlayan sallama kemer adı verilen tokalar kullanılmıştır bunun yanında aksesuar ve takılarda da çeşitlilik görülmektedir. (Kuru, 2003, s. 559).

Fotoğraf 1. Üç Etek Tosya Geleneksel Kadın Giysi Örneği.

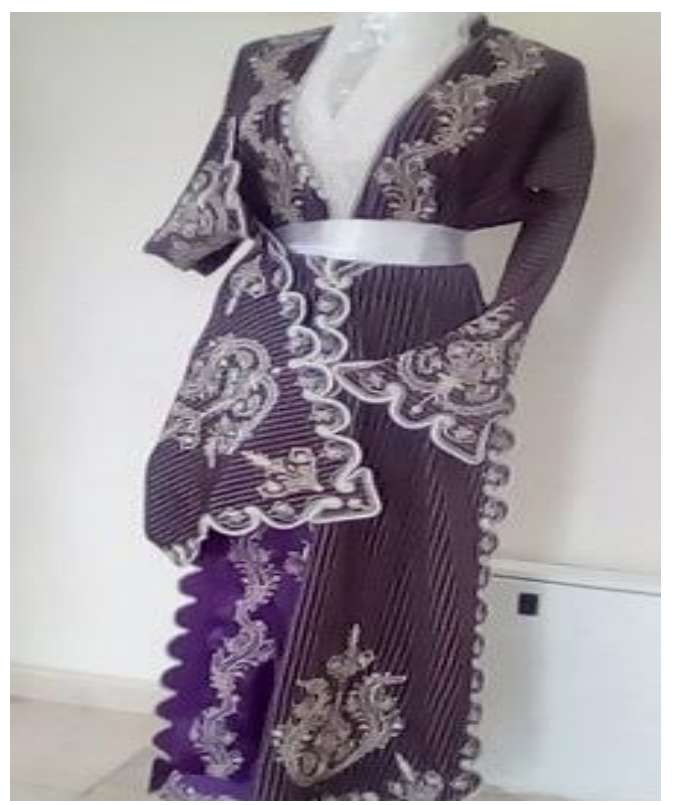

Kıstı, Tosyalı Ermeni ustaların Tosya'ya kazandırmış olduğu bir takı sanatıdır. Standart bir Kıstı 33 Ayak ve 34 Kent'ten oluşmaktadır ancak bunun yanı sıra arkaya kadar uzatılan Kent'ler ile 33 ayak ve 58 kenet ile de kıstı üretimi yapılmaktadır. Ayak, Kıstı 'nın ana motifidir 
ve kentler ile boyun üzerine sarkar. Genellikle balık motifi olan ayaklar, kesin olmayan bilgilere göre Şahmeran'dan esinlenerek oluşturulmuştur ve boyu $2 \mathrm{~cm}^{\prime}$ dir. Kent ise, incilerle birlikte yan yana dizilen ve ayak kısmını tutan, boynu sarmalayan kısımdır. Kentler fiyonk şeklindedir ve yaklaşık $1 \mathrm{~cm}$ uzunluğundadır ( Er ve Sarıkaya, 2018 s.45).

\section{Fotoğraf 2. Tosya Geleneksel Kıstı Takısı Örneği.}

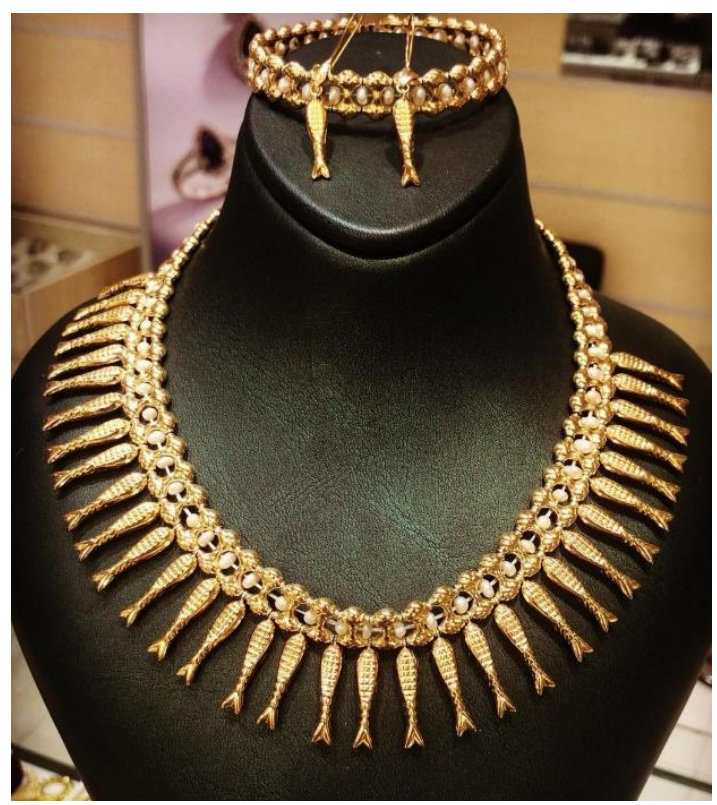

Geleneksel kültürde önemli bir yeri olan geleneksel kadın başlıkları, günümüzde ancak dügünlerde ve özel etkinliklerde kullanılmaktadır. Bu araştırmada Kastamonu ili Tosya ilçesinde yaşatılmaya çalışılan geleneksel kadın baş süslemeleri incelenmiştir. Başlıkların ürün özellikleri, geleneksel kültürdeki yerinin gelecek nesillere aktarılması ve kaynak oluşturması açısından bu başlıkların özellikleri ve onarımı araştırma problemi olarak ele alınmıştır.

Kültürel mirasın yaşatılması ve gelecek nesillere Türk milli kimliğinin aktarılmasının en somut örneği olan geleneksel başlıklarımız şüphesiz çok önemlidir. Bu nedenle bu araştırmada Tosya ilçesinin geleneksel kadın başlıklarını ele alınarak kültürel mirasın sürdürülebilirliğinin sağlanması amaçlanmıştır.

Araştırmada, Tosya geleneksel kadın başlıkları konusunda bugüne dek yapılan çalışmalara ait kaynaklar çerçevesinde değerlendirilerek, başlıklar konusundaki verilerin bir araya getirilmesi amaçlanmaktadır.

Kültürel öneme sahip bu araştırmada; Tosya ilçesi geleneksel kadın başlıklarının önemi, geleneksel başlıkların özelliklerinin yorumlanması, turistik ürün olarak tasarlanması ve sürdürülebilirliğinin sağlanması amaçlanmıştır. 
Fotoğraf 3. Turistik ürün olarak tasarlanan broş, küpe ve kolye örnekleri.
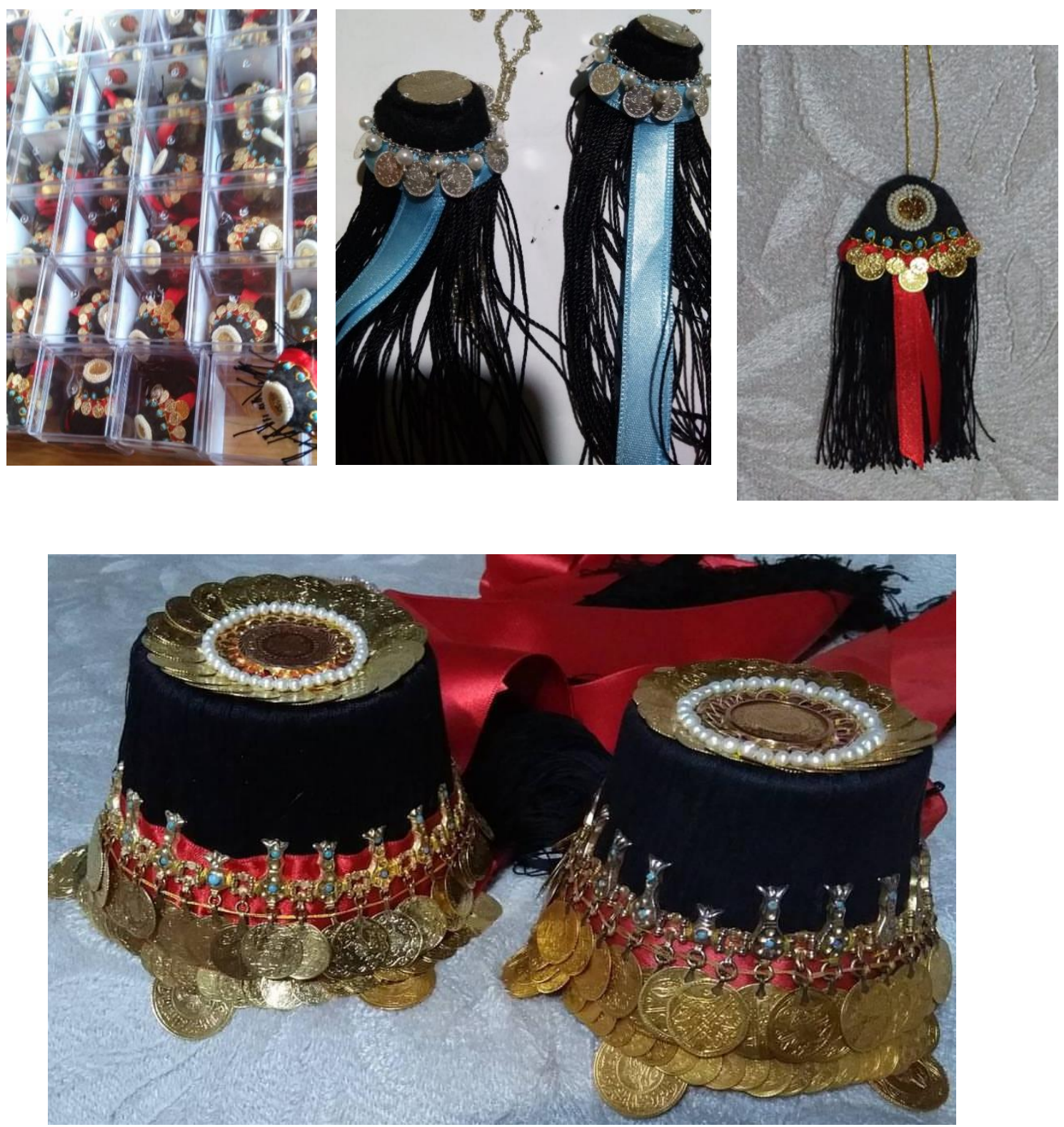

Tosya ilçesinde geleneksel özelliklere bağlı kalınarak geçmişten günümüze birer somut belge niteliği taşıyan yöresel kadın başlıkları varlığını devam ettirmektedir. Yöresel başlıklar, gerek bazı özelliklerinden uzaklaşmasından, gerekse günümüzde kaybolmaya yüz tutan malzemelerin sınırlılığından dolayı hızla yok olmaktadır. Zengin bir kültür unsuruna sahip olan Tosya ilçesi geleneksel kadın başlıkları, kendine özgü nitelikleriyle önemli bir değer kazanmıştır. Bu başlıklar kullanılan malzeme özellikleri incelendiğinde, bölgenin sosyal yapısını gösteren en değerli kültürel miras belgeleridir. Bu çalışma ile yöresel Tosya kadın başlıklarının doğru olarak tespit edilip belgelenmesi sağlanacaktır. Çalışma var olan kültürel miras değerlerimizi yaşatmak ve ülke tanıtımına yarar sağlaması açısından önemlidir. 


\section{YÖNTEM}

Araştırma kapsamında Tosya ilçe sınırlarında saha çalışması yapılmıştır. Yapılan saha çalışmasında, ulaşılan Tosya yöresi geleneksel Tosya kadın başlıkları; Tosya ilçesi ziyaret edilerek yerinde incelenip fotoğraflanmıştır. İlçe'de Tosya başlıkları üzerinde çalışan Nevin Tahtacı ile görüşülmüş, sandıklarda korunan başlıklar incelenip fotoğraflanmıştır. Tosya başlığında kullanılan araç gereçler ve işlem basamakları sırası ile gözlemlenerek yapım aşamaları incelenmiştir. Daha sonra ilçede bulunan Tosya Halk Eğitim Merkezine bağlı Geleneksel giysi kursları ziyaret edilip başlıklar ve gelin kıyafetleri incelenerek bilgi formları oluşturulmuştur.

Kastamonu ili Tosya ilçesinde bulunan geleneksel kadın başlıklarının incelenerek literatüre katkıda bulunması amacıyla yapılan bu araştırma, tarama modelinde betimsel bir çalışmadır.

Araştırmanın evrenini Kastamonu İli Tosya İlçesinde bulunan başlıklar; örneklemini ise Tosya ilçesinde bulunan ve rastgele seçilen farklı özellikte beş adet geleneksel süslemeli ürün oluşturmuştur.

Çalışma kapsamında geleneksel başlıklarla ilgili literatür taraması yapılmıştır. Kastamonu ili Tosya ilçesinde bulunan bazı geleneksel başlık örnekleri incelenerek, bu ürünlere ait özellikler ve verilerin kaydedilmesi amacı ile araştırmacı tarafından hazırlanan bilgi formlarından elde edilen veriler kaydedilmiştir.

Literatür taraması ve gözlem yapılarak toplanan bilgiler, amaçlar doğrultusunda doğrudan ve dolaylı alıntılar yapılarak da desteklenmiştir. Kastamonu ili Tosya ilçesinde bulunan geleneksel başlık ürünlerinin incelenmesi sonucunda bazı bulgular elde edilmiş ve elde edilen veriler doğrultusunda ürünler bilgi formları halinde sunulmuştur.

\section{BULGULAR}

Kastamonu ili Tosya ilçesi geleneksel kadın başlıklarında kullanılan malzemeler incelendiğinde; genel olarak iç kısım da keçe kullanıldığı görülmektedir. Dış kısım da ise kalıp kullanılarak kumaştan dikilen fesin üstüne siyah renk iplikle çiçek motifleri, kanaviçe tekniği ile işlenmiştir. İşleme kurdele, inci ve gümüşlerle süslenmiştir. Yapım tekniği açısından kalıp çıkarma, kesme, iplik sarma ve düğüm atma gibi farklı teknikler kullanılmaktadır. Genel yapım tekniği olarak bağlama ve ip gerdirme tekniği en çok kullanılan tekniklerdir. Süsleme için altın ve inci kullanımının oldukça fazla olduğu gözlenmiştir. Fesin yan uçlarında yarısı üstüne binecek şekilde sık dizilen gümüş paralar, iki sıra üst üste olacak şekilde dizilmiştir. İki sıra gümüş paraların altından sarkan üç büyük gümüş para, alnın ortasına ve iki yana gelecek şekilde dikilmiştir. Fesin tepesinde ise, karton üzerine ortada bir büyük gümüş paranın çevresine bir sıra inci, onunda çevresine uçları üst üste gelecek şekilde tekrar altın veya gümüş para dizimi yapılmıştır (Resim 1.).

\section{Tosya Geleneksel Kadın Başlıklarının Yapımında Kullanılan Malzemeler}

\begin{tabular}{ll} 
- & Kalıp \\
- & Keçe \\
- & Kırmızı saten kurdele \\
- & İnci \\
\hline & Zilifbastı ( Altın)
\end{tabular}

- $\quad$ İplik çeşitleri

- Tarak

- $\quad$ Püskül iplikler

- $\quad$ Tiğ

- $\quad$ İğne 
- $\quad$ Mavi boncuk

- Penez

- Altın

- $\quad$ Mecidiye altın

- Gümüş takılar

- $\quad$ Kalem

- $\quad$ Cetvel

- $\quad$ Çizim sabunu

- Tahta

- $\quad$ Kemik Tarak Tokası

\section{Tosya Geleneksel Kadın Başlıklarının Yapım Aşamaları}

Fotoğraf 4. Başlık yapımında kullanılan kalıp çıkarma ve keçe dikimi.
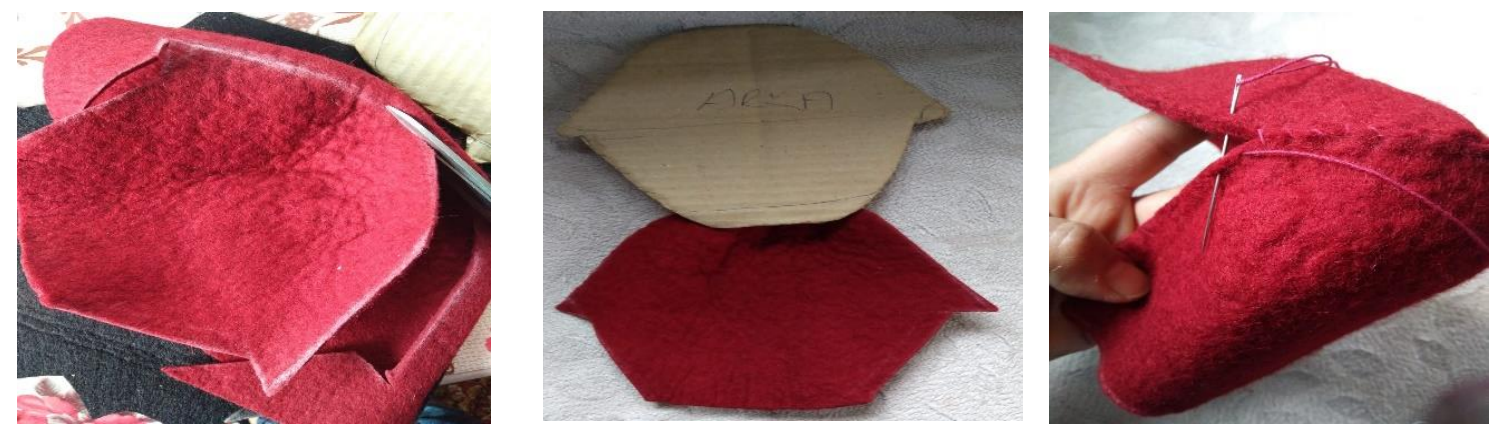

Fotoğraf 5. Kenarların iplikle hazırlanması ve dikim işlemi.
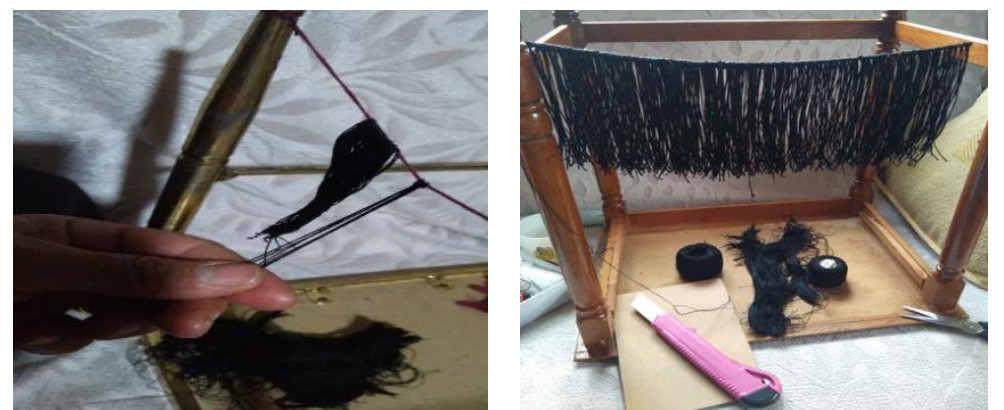

Fotoğraf 6. Başlı̆̆ın tepe kısmının karton kalıba dikim işlemi.
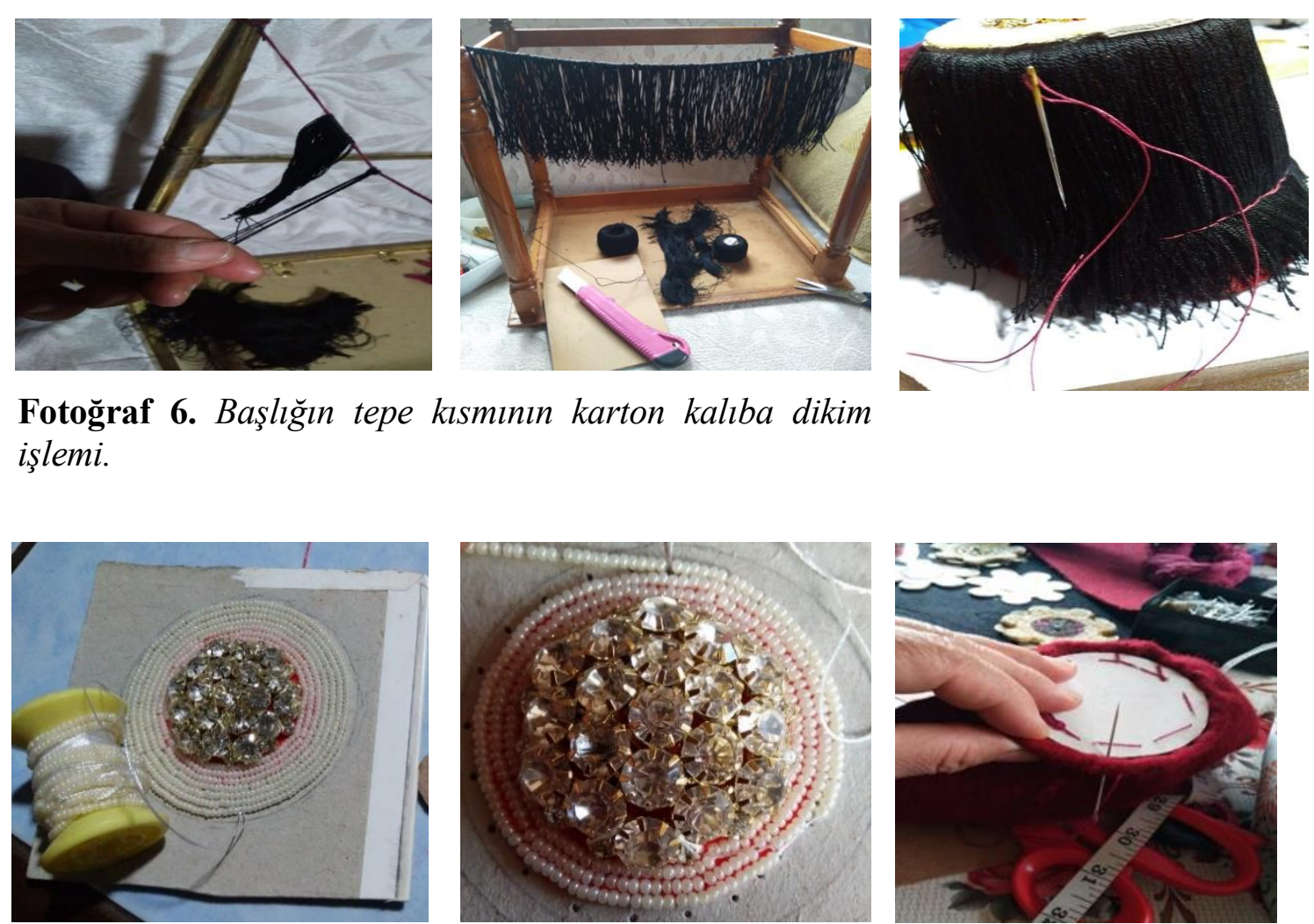
Fotoğraf 7. Başlı̆̆ın kenar kısmına zilif bastı ve altınların dikim işlemi.
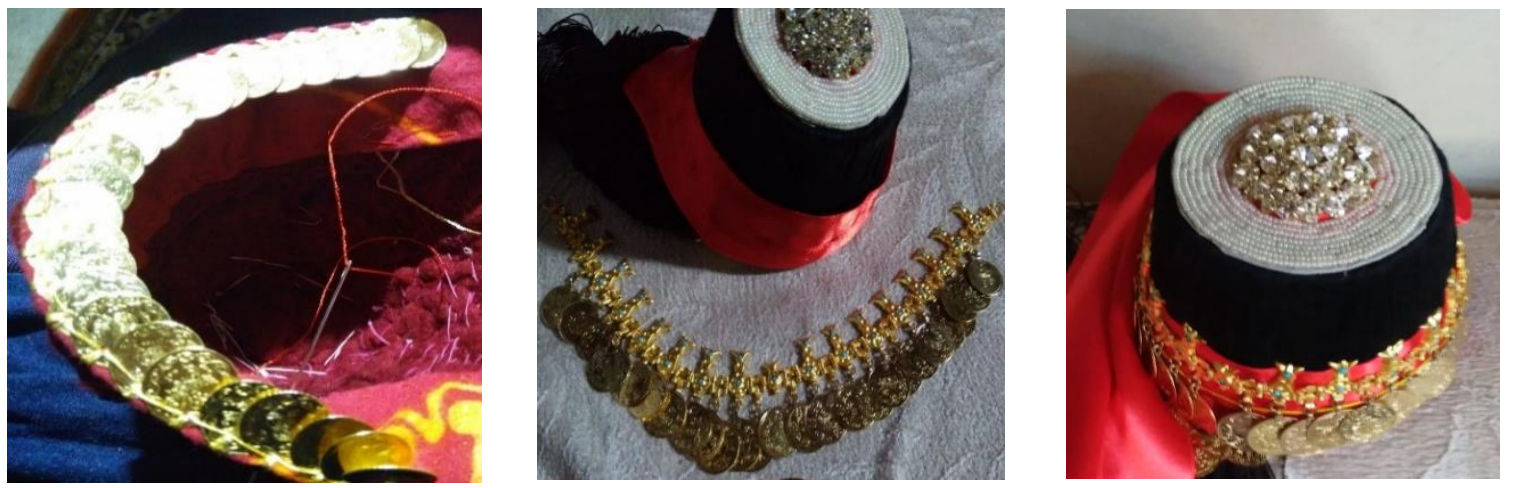

Tosya ilçesinde aslına bağlı kalınarak geçmişten günümüze sürdürülen yöresel kadın kıyafetleri ve başlıkları halen özel günlerde giyilmektedir. Tosya ilçesinde bindallı ve üç etek olmak üzere iki farklı çeşitte kıyafet giyilmektedir. Bindallı; fes, şalvar ve göynek ile birlikte giyilmekte ve bel kısmına gümüş kemer takılmaktadır. Diğer kıyafet ise tek parça olarak giyilmektedir. Her iki kıyafetti altın ve incilerle süslenen başlık tamamlamaktadır.

Fotoğraf 8. Dival işi Bindallı, Üç Etek ve Tosya Başlığı örneği.

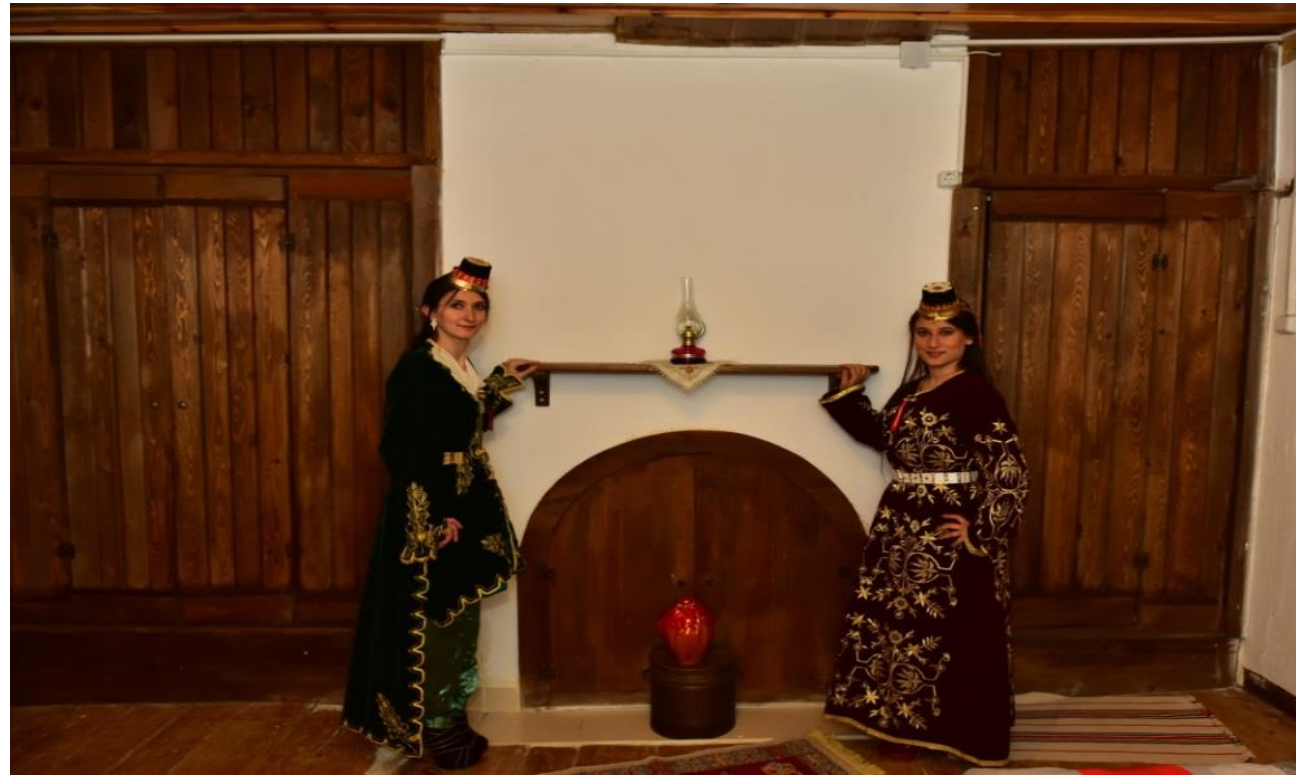

Başlığın tepe kısmında, çiçek şeklinde kesilen mukavva karton üzerine modele göre büyük altın ve inci dikildiği görülmektedir. Motif olarak çiçek motifi belirgin olarak göze çarpmaktadır. Başlıkların boyutunun 10x15 cm olduğu ve yapımında özellikle gerçek altının kullanıldığı yapılan araştırma sonucunda elde edilen bulgulardır. Başlık örneklerinde siyah, kırmızı, mavi, yeşil ve sarı renklerin çoğunlukta olduğu ayrıca başlıkta kullanılan altın (Zilifbastı) miktarının ailenin maddi durumuna göre değişkenlik gösterdiği ve gümüş kullanımının ise az da olsa devam ettiği tespit edilmiştir. 


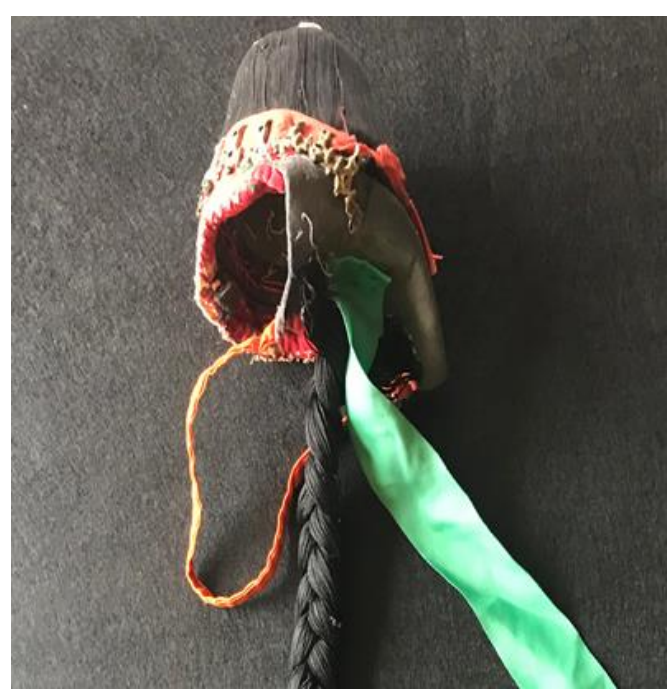

- Bilgi Formu

- Onarıma Geldiği Tarih

- Ürünün Adı

- Ebat

- En x Boy

- Dokuma

- Kullanilan Teknikler

- Kullanilan Renkler

- Kenar Temizleme Tekniği

- Kullanilan Kompozisyon Özellikleri

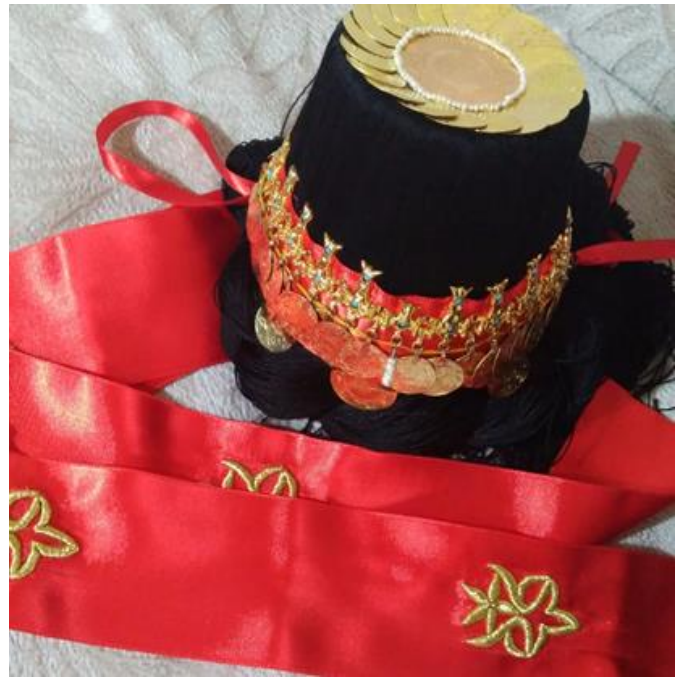

$: 01$

: 10.03.2019

: Fes Başlık

:10x15cm

: Keçe

: Bağlama Tekniği

: Siyah, Kırmızı, Mavi, Sarı

: Saçak kesme

: Altın çevirme

Kenarlara doğru genişleyen başlığın iç yüzü keçe ile kaplanmıştır. Kenar kısmı zilif bastı, tepe kısmı ise büyük altının etrafı inci ile bir sıra geçilerek, yine sıralı altın ile süslenmiştir. Başlığın arka kısmı kırmızı kurdele ve saç görünümü vermek için eklenen uzun püskül tamamlanmıştır. Orijinalinde kullanılan renkler ve model değiştirilmiştir.

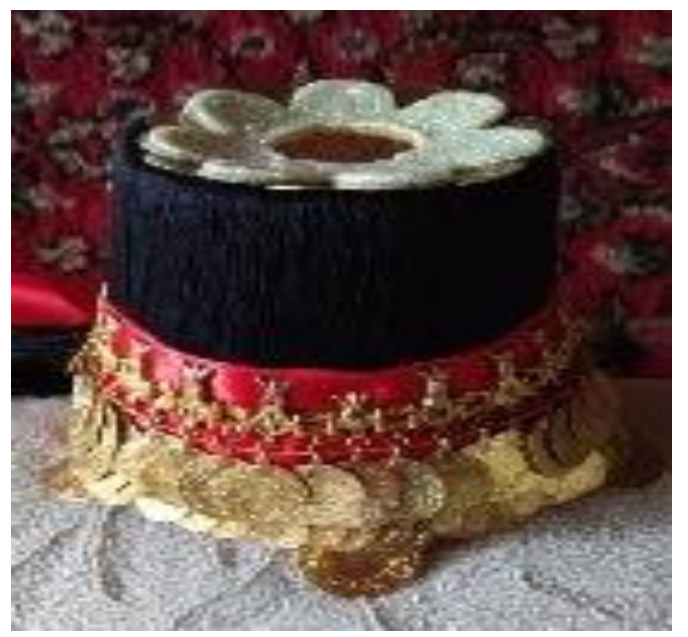

- Bilgi Formu

- Onarıma Geldiği Tarih

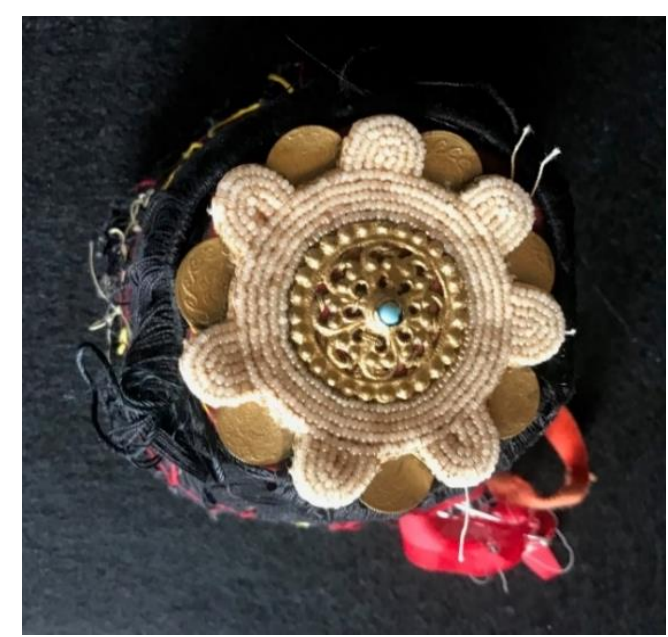

$: 02$

:08.04.2019 
- Ürünün Ad1

- Ebat

- En x Boy

- Dokuma

- Kullanilan Teknikler

- Kullanilan Renkler

- Kenar Temizleme Tekniği

- Kullanilan Kompozisyon Özellikleri
: Fes Başlik

$: 10 \times 15 \mathrm{~cm}$

: Keçe

: Bağlama Tekniği

: Siyah, Kırmızı, Mavi, Sarı

: Saçak kesme

: Çiçek Dolama

Altın ve inci sıralı papatya modelli başlık, alt yapısı ile birlikte yenilenmiştir. Zemin kısmında kullanılan keçe, siyah iplik ile kenarları taranarak ve ekleme yapılarak onarılmıştır. Üzerinde bulunan altın ve inciler papatya modeline uygun olarak tekrar düzenlenip, başlığa dikiş tekniği ile eklenmiştir. Kenarlarda kullanılan zilif bastı, alt kısma gelecek şekilde altınlar ile sıralanmış ve son olarak kırmızı kurdele ve örgü şeklinde uzun iplik ile başlık tamamlanmıştır.

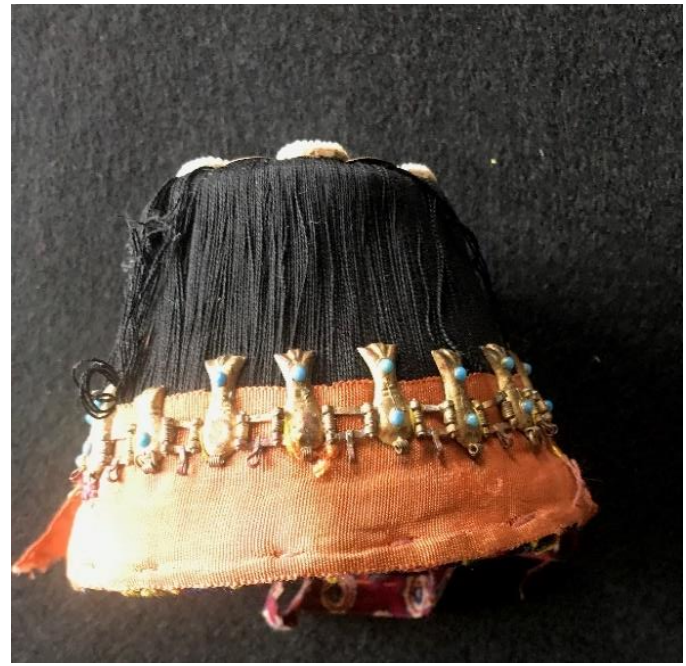

- Bilgi Formu

- Onarıma Geldiği Tarih

- Ürünün Ad1

- Ebat

- En x Boy

- Dokuma

- Kullanılan Teknikler

- Kullanilan Renkler

- Kenar Temizleme Tekniği

- Kullanılan Kompozisyon Özellikleri

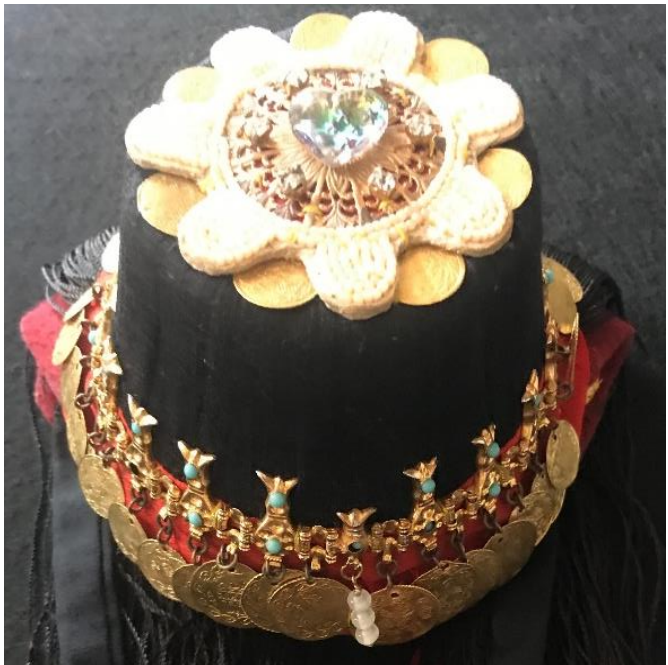

:03

: 15.04 .2019

: Fes Başlık

$: 10 \times 15 \mathrm{~cm}$

: Keçe

: Bağlama Tekniği

: Siyah, Kırmızı, Mavi, Sarı

: Saçak kesme

: Altın ve inci sıralamalı kompozisyon

Başlığın tepe kısmında bulunan kalp şeklindeki elmas taşından dolayı, model kalpli model olarak tanımlanmaktadır. Ayrıca Penez olarak adlandırılan tepe kısımdaki takı, oldukça az kullanılmaktadır. Başlığın etrafını saran siyah ipliklerin deforme olmasından dolayı kenar iplikler yenilenmiştir. Ayrıca kenarında bulunan zilif bastı parlatılarak kurdele üzerine tekrar dikilerek başlığın orijinal hali korunmuştur. Çiçek modeli için inci kullanılmış ve alt zemini 
altın ile desteklenmiştir. Alt yan kısımlarda kullanılan zilif bastıya 16 ayar 32 altın dikilmiş ve iplik saç eklenerek başlık tamamlanmıştır.

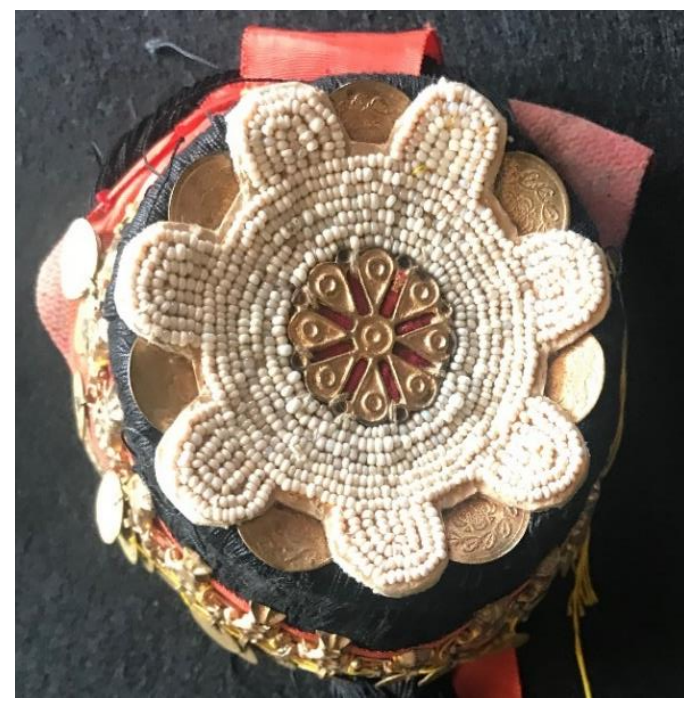

- Bilgi Formu

- Onarıma Geldiği Tarih

- Ürünün Ad1

- Ebat

- En x Boy

- Dokuma

- Kullanilan Teknikler

- Kullanilan Renkler

- Kenar Temizleme Tekniği

- Kullanilan Kompozisyon Özellikleri kompozisyon

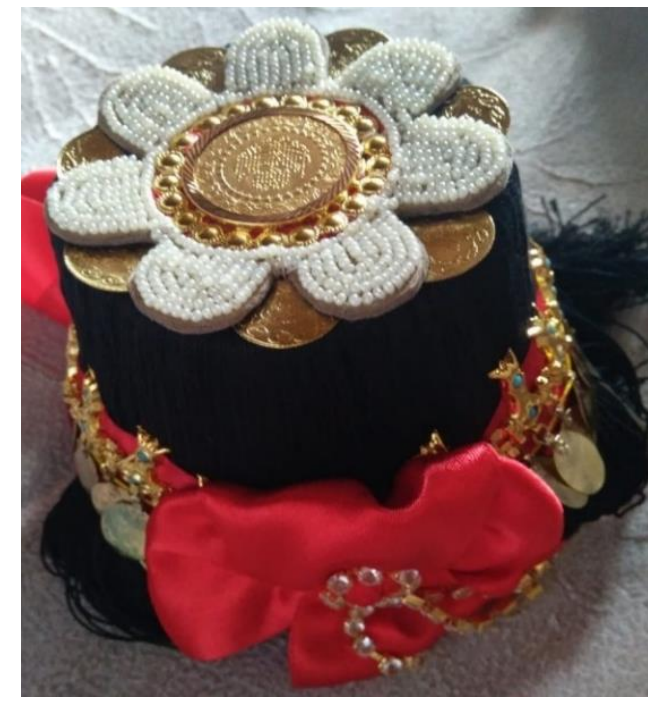

$: 04$

: 18.03.2019

: Fes Başlık

$: 10 \times 15 \mathrm{~cm}$

: Keçe

: Bağlama ve Dikme Tekniği

: Siyah, Kırmızı, Mavi, Sarı

: Saçak kesme

: Altın ve inci sıralamalı

Çiçek modelli başlığın tepe kısmına altın yerleştirilmiş ve inci boncuklarla papatya modeli oluşturulmuştur. Kenarlarının iplikleri yeniden taranıp, zilif bastı parlatılmıştır. Alt kısma altınlar yan yana dikilip yaklaşık $80 \mathrm{~cm}$ uzunluğunda kırmızı kurdele ve siyah uzun püskül ile süsleme işlemi yapılmıştır. 


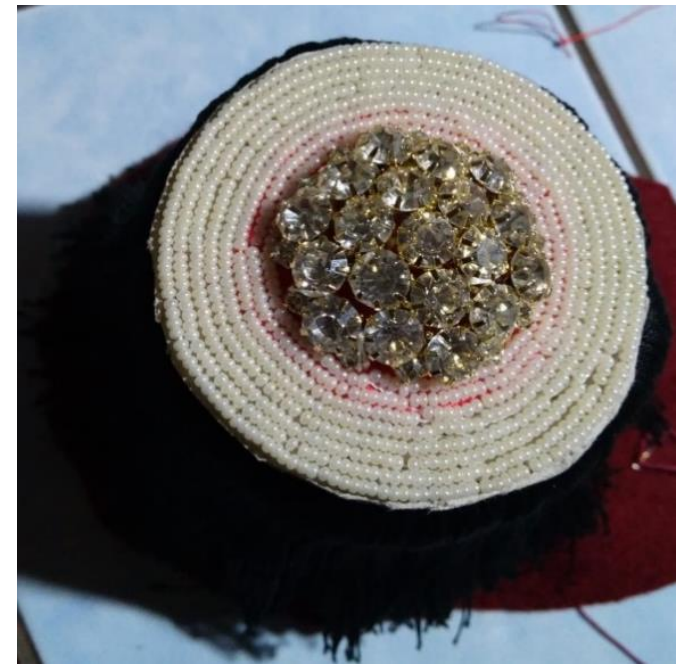

- Bilgi Formu

- Onarıma Geldiği Tarih

- Ürünün Ad1

- Ebat

- En x Boy

- Dokuma

- Kullanilan Teknikler

- Kullanilan Renkler

- Kenar Temizleme Tekniği

- Kullanılan Kompozisyon Özellikleri

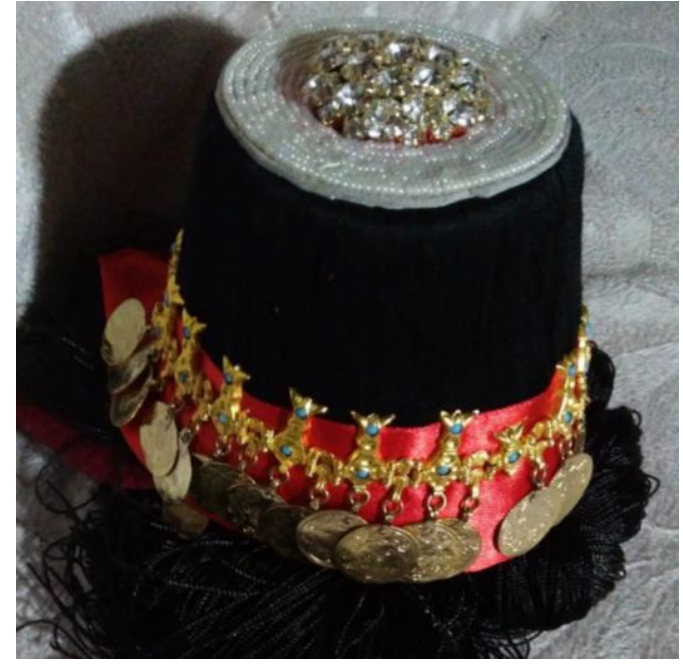

$: 05$

: 21.04.2019

: Fes Başlık

$: 10 \times 15 \mathrm{~cm}$

: Keçe

: Bağlama Tekniği

: Siyah, Kırmızı, Mavi, Sarı

: Saçak kesme

: İnci sıralamalı kompozisyon

Keçe üzerine iplikle kaplama işleminden sonra, tepe kısmı tekrar kullanılmıştır. Dış yüzeyi n alt kısmı altın ve zilif bastı ile süslenmiş ve sarkan şekilde altın dizilmiştir. Süsleme daha çok inci ile yapılarak başın bir yanına gelen kurdele ve püskül ile başlığın iç yüzüne yan yana yerleştirilmiştir.

\section{TARTIŞMA, SONUÇ ve ÖNERILER}

Geleneksel kadın başlıkları, içinde yaşanılan topluma, zamana, geleneklere ve zevklere göre şekillenmiştir. Halk kültürünün konuları arasında yer alan geleneksel başlıklar, geleneksel mirasımızın gösterişli kültür ürünleri olmuşlardır.

Günümüz toplumunda yaşam şartları birçok nedenden dolayı değiştiği için yöresel kıyafet kullanımı bir çok bölgemizde artık tercih edilmemektedir. Teknolojinin gelişmesi, ulaşılabilirlik ve giysilerin kullanım zorluğu gibi pek çok nedenden dolayı geleneksel kıyafetler, eski anlam ve önemini yitirmekte ve kaybolmaya yüz tutmaktadır.

Kastamonu ili Tosya ilçesinde yöresel kıyafet ve başlıklar özel günlerde halen giyilmekte ve yöre halkının yaşantısında geçmişin gelenek ve göreneklerine sadık kalınarak varlığını sürdürmektedir. 
Araştırma sonucunda kullanılan malzemenin özellikle aksesuarların, ailenin maddi durumuna göre değişkenlik gösterdiği belirlenmiştir. Kullanılan malzemeler arasında özellikle altın ve gümüşün ağırlıklı olarak kullanıldığı gözlenmiştir. Başlıkların döneme, kişiye ve maddi duruma göre değişiklik gösterdiği belirlenmiştir. İlçede Geleneksel Başlık Ustası Nevin Tahtacı bu işi sürdürmektedir.

Tosya ilçesinde iki farklı çeşitte dival işi ile işlenmiş Bindallı klyafeti, fes ile birlikte giyilmektedir. Düğünlerde geline takılan fes üzerine kırmızı kurdele dikilmektedir. Bindallı kıyafeti gümüş kemerle desteklenmekte ve yüksek ökçeli ayakkabı ile giyilmektedir. Tosya ilçesinde başlıklar genellikle genç kızlar tarafından kına gecelerinde geleneği devam ettirmek amacıyla kullanılmaktadır. Yeterli tanıtım yapılmaması ve ilgili kurumlarca maddi olarak desteklenmediğinden bu başlıklara ilgi giderek azalmaktadır.

Kültürel miras varlıklarımızdan biri olan geleneksel kadın başlıkları, bir çok sebepten dolayı giderek yok olmaktadır. Toplumun yaşam biçimini simgeleyen kadın başlıklarının incelenmesi ve belgelenmesi, gelecek nesillere tanıtılması ve yaşatılması açısından çalışma önem taşımaktadır. Bu nedenle kaybolmaya yüz tutmuş kültür değerlerimizden biri olan geleneksel kadın başlıklarının araştırılması ve günümüze ulaşabilen örneklerinin incelenmesi oldukça önemlidir. Araştırmanın, geleneksel başlık alanındaki çalışmalara katkı sağlayacağı düşünülmektedir.

\section{KAYNAKÇA}

Balta, N. (2014). Anadolu kadın başlıkları. Ankara: Erek matbaacılık.

Erdem, Ş. (2003). Kastamonu ilinde geleneksel kadın erkek kıyafetleri. Kastamonu Kültür Seтроzуuтu, 18-20 Eylül, , s. 563-574. Ankara.

Kancan, D. (1998). Sivrihisar ilçesi geleneksel kadın giyim-kuşam özelliklerinin incelenmesi. Yayımlanmamış yüksek lisans tezi, Sosyal Bilimler Enstitüsü, Gazi Üniversitesi, Ankara.

Kuru, S. (2005). Kastamonu yöresi geleneksel kadın giyiminin geleneksel Anadolu kadın giyimi içerisindeki yeri. İkinci Kastamonu Kültür Sempozyumu Bildirileri, 18-20 Eylül 2003, s.557-562. Ankara: Gazi Üniversitesi İletişim Fakültesi Basımevi.

Kazıcıoğlu, N. (1994). Üzümlü örneğinde yaşanan el dokumalarındaki bozulma nedenleri ve çözüm önerileri. Kamu ve Özel Kuruluşlarla Orta Öğretimde Üniversitelerde El Sanatlarına Yaklaşım ve Sorunları Sempozyumu Bildirileri, 18-20 Kasım, İzmir. Ankara: Türk Tarih Kurumu Basımevi.

Özus, E., Erden, F. ve Tufan, M. (2014). Malatya yöresi geleneksel kadın kıyafetlerden günümüze yansimalar. International Journal of Sience Culture and Sport, 2(Special Issue 1), 650-664.

Özbağı, T, N. , Ülger, Kurt, G. ve Toktaş, P. (2007). Anadolu Üniversitesi Halkbilim Araştırmaları Merkezi koleksiyonundan el sanatları örnekleri I işlemeler. Eskişehir: Anadolu Üniversitesi.

Özder, L. (1995). İ̧ Anadolu Bölgesi geleneksel kadın başlıkları ve çeşitli özellikleri. Yayımlanmamış doktora tezi, Gazi Üniversitesi Eğitim Bilimleri Enstitüsü, Ankara.

Er, B. ve Sarıkaya, Z. (2018). Kastamonu ili Tosya ilçesi geleneksel kıstı takısı. Kalemisi Dergisi, 6(11), 41-54. 
Er, B. ve Sarıkaya, Z. (2017). Kastamonu ili Tosya ilçesinde kadın baş süsleme geleneği. II. Uluslararası Akdeniz'de Güzel Sanatlar Çalıştayı, Antalya- Belek.

\section{Kişi Kaynakları}

Nevin Tahtacı (2019). Lise Mezunu, 1974 doğumlu, Tosya Geleneksel Başlık Ustası. Kastamonu, 04.25.2019 tarihinde görüşülmüştür.

Nuray Oruç (2019). Tosya Halk Eğitim Üç Etek Kursu Öğreticisi.

Sefa Leblebici (2019). Tosya Kıstı Ustası ve Kuyumcu. Kaynak Kişi. 